\title{
New Contributions of the Rorschach Method on the Effects of Sexual Abuse in Childhood
}

\author{
Silvana Alba Scortegagna1, Rosangela Kátia Sanches Mazzorana Ribeiro², \\ Anna Elisa Villemor-Amaral ${ }^{3}$ \\ ${ }^{1}$ Universidade de Passo Fundo, Passo Fundo, Rio Grande do Sul, Brazil \\ ${ }^{2}$ Universidade Federal de Mato Grosso, Cuiabá, Mato Grosso, Brazil \\ ${ }^{3}$ Universidade São Francisco, Itatiba, São Paulo, Brazil \\ Email: silvanalba@upf.br
}

Received 30 December 2015; accepted 14 February 2016; published 17 February 2016

Copyright (C) 2016 by authors and Scientific Research Publishing Inc.

This work is licensed under the Creative Commons Attribution International License (CC BY).

http://creativecommons.org/licenses/by/4.0/

(c) (i) Open Access

\begin{abstract}
This study aimed to verify the effects of sexual abuse and maternal abandonment and to explore the utility of the Rorschach method to understand the victims' interior life. The qualitative analysis focused on 12 protocols of children between six and eight years of age, including five girls and seven boys from Brazilian institutions. The presence of recursive responses of inanimate movement (m), morbid (MOR), aggressive (AG), sexual (Sx) contents and anatomy (An) was evidenced. The results suggest traumatic experiences with primary objects, hostile and aggressive human interactions, damaged self-perception and early abusive sexualization. The findings illustrate the harmful effects of sexual abuse and maternal abandonment in child development, and ratify the use of the Rorschach for evaluation processes in an ideographic approach, beyond the nomothetic perspective.
\end{abstract}

\section{Keywords}

Developmental Psychology, Projective Personality Measures, Victimization, Qualitative Assessment

\section{Introduction}

Sexual abuse in childhood results in short and/or long-term psychological problems. Since the 1980's, several authors have proposed conceptual models to explain the harmful effects and factors associated with sexual abuse. Among the pioneers, Finkelhor and Browne (1985) developed the theory of traumatic dynamics, which consists of four factors: traumatic sexualization; treason, impotence and stigmatization Traumatic sexualization involves 
the inappropriate development of childhood sexuality, resulting in compulsive sexual behaviors and confusion on the sexual identity. Treason occurs when the child perceives the exploration by a person who should be trustworthy or when a non-abusive family member is unable to protect him/her. When figures of trust are lost, the victims can present responses of mourning and depression, and increased responses of hostility and anger. Impotence appears when the child's attempts to avoid or put an end to the abuse are ineffective, resulting in feelings of fear, anxiety and incapacity. Finally, the stigmatization of abuse experiences is strengthened by other people's attitudes of depreciating and blaming the victims.

Alexander $(1992,2009)$ proposed a theoretical model from the perspective of developmental psychology, suggesting that sexual abuse interferes in individual and social development. He states that the effects of sexual abuse can be understood in the context of Bowlby's $(1973,1980)$ theory of attachment, with important repercussions for the way the victims establish affective bonds. The child's attachment can be defined as an affective bond (s) he establishes with the primary caregivers during the first years of life, which serves as the base for the elaboration of a dynamic internal model. This internal model of functioning remits to mental representations of the self, others and the world, as a prototype of the relations constituted in the course of life.

Therefore, individuals victims of incestuous sexual abuse during childhood experience the lack of responsive and solidaristic parents, capable of providing support for development of a safe bond, a mental construction that constitutes the base of personality (Alexander, 2009). In this context maternal support is specially important because it is considered a strong predictor of psychosocial recovery of children victims of sexual abuse after the complaint (Cassidy \& Mohr, 2001; Lamb \& Edgar-Smith, 1994; Smith et al., 2010). It is positively associated with a better response to the intervention (Cohen \& Mannarino, 2000), low levels of childhood depression (Zajac, Ralston, \& Smith, 2015) and lesser risk of using illegal drugs (Bick, Zajac, Rakton, \& Smith, 2014; Hadland et al., 2012).

Despite conceptual limitations regarding, maternal support is defined as a multidimensional construct, which consists in the mother's protective action to avoid the continuing victimization and in the search for appropriate intervention (Smith et al., 2010). A response that is considered positive or supportive is characterized by the empathic concern and credibility granted to the victim, while negative and unsupportive responses are characterized by blaming the victim, denial or minimization of the abusive event and maternal abandonment (Lamb \& Edgar-Smith, 1994). Non-existent or insufficient maternal support and repetitive episodes of childhood mistreatment tend to have a pervasive effect in the victim's development (Cassidy \& Mohr, 2001).

In this horizon, the alert is raised that a traumatic situation provoked by a person with a strong affective bond of proximity and dependence, like the mother or the first objects of love, tends to provoke more severe damage in the mental constitution than if the experience originated in an impersonal relationship (Briere, 2004; Molnar, Buka, \& Kessler, 2001). Besides the problems in the mental constitution, it can make the victims experience more difficulties to reveal the abuse (Scortegagna \& Villemor-Amaral, 2012) and be more prone to engage in drugs use (Hadland et al., 2012).

Although studies have demonstrated the association between maternal support and childhood adaptation in cases of victimization, the findings reveal inconsistencies. The incongruences are basically justified by the lack of evidences of validity of the tools used (Bick et al., 2014; Hadland et al., 2012). Beyond the use of self-reported instruments and to unveil results that can support the findings or not, next, studies will be presented that use the Rorschach in cases of childhood victims.

\section{Rorschach Indicators of Victimization and Sexual Abuse of Children}

Focusing on children, Gravenhorst (2002) in Argentina aimed to understand the psychological trauma of victims of sexual abuse between four and 16 years of age. The analysis of Rorschach protocols showed the presence of blood contents, sexual responses and morbid content. Among the examples, the responses of a six-year-old girl stand out, who was sexually abused by her father: "it looks like a mouse that was killed", "the shape of the legs and head”, "he’s dead because I see that he was crushed”, "his insides were eaten, it's all open!”. The author refers to the oral complex and morbid content responses, which reveal melancholic oral experience associated with sexuality. The occurrence of a high score for unusual and uncommon responses, such as sex and blood, in other studies (Friedrich, Jaworski, Huxahl, \& Bengston, 1997; Kendall-Tackett, Williams, \& Finkelhor, 1993) suggests the presence of anguish and severe body damage of childhood sexual victims, which affect the mental world. These responses generally appoint the feeling of vulnerability and an exposed, unprotected and destroyed body. 
In line with some of the findings reported, the study by Scortegagna and Villemor-Amaral (2009) in Brazil presented significant increase of the inanimate movement $(m)$ and blood content $(B l)$ among sexual abuse victims between 10 and 14 years of age. Concerning the $m$, it is already recognized as one of the markers of traumatic events (Kaser-Boyd \& Evans, 2008). The anatomy (An), morbid (MOR), sexual content (Sx) and formally distorted (FQ-) responses were significantly more frequent in sexual abuse victims and revealed the presence of a distorted self-perception, reduced self-esteem and profound feelings of vulnerability and lack of protection (Exner, 2003; Weiner, 2003).

To further the understanding of the results found, the authors developed a qualitative analysis of the Rorschach responses $\mathrm{m}$ and $\mathrm{Bl}$ content, present in 29 protocols. In the victims' expressions, the following were observed: i) $m$ responses suggesting feelings of abandonment and impotence, for example, "nest... it's breaking, falling apart", "an explosion in the sea of war", "an explosion in the water", "tree falling on the floor"; ii) responses with $m$ or $B l$ associated with much more violent or destructive contents, for example, "some droplets of blood are falling", "the blood is dripping, lots of blood falling on the people"; iii) images loaded with morbid characteristics, for example, "dog run over", "crushed frog”, "a crushed mouse”, "a crushed bat”, "dead animals" (Scortegagna \& Villemor-Amaral, 2013). The authors concluded that the frequent expressions containing $\mathrm{m}, \mathrm{Bl}$ and MOR show the perception of a lifeless, damaged or undignified body, a fragmented sense of self, indicators that reveal the damage suffered much more acutely. Coherently with the background literature, they may be expressing signs of lack of prohibition, of an adverse environment, and of violence against the body passively undergone (Gravenhorst, 2002; Perfect, Tharinger, Keith, \& Lyle-Lahroud, 2011).

Another recent study investigated the relation between the experiences of sexual abuse and mental health problems in 44 African-American children, between 6 and 15 years old in the initial assessment, and 15 months later (Barnett, Heinze, \& Arble, 2013). Among the results, the responses of Sx content on the Rorschach-SC (Exner, 2003) indicated poor prognosis in relation to symptoms of depression. Examples of these narratives included "vaginal area", on card II, and "two males... here are their penises", on card III. The Sx content was considered a more suggestive than conclusive predictor of depressive symptoms.

Although these results indicate the importance of the Rorschach method to investigate the effects of sexual abuse, the findings should be expanded and constantly reviewed in different contexts. Therefore, this study aimed to verify the effects of sexual abuse and maternal abandonment in a group of victimized children and to add new considerations on the utility of the Rorschach method for this purpose.

\section{Method}

\subsection{Source}

Twelve protocols of sexual abuse victims were analyzed, between six and eight years of age, five girls and seven boys, with low socioeconomic levels, from institutions located in the state of Mato Grosso (MT) and Rio Grande do Sul (RS), Brazil. The children had been victims of recurring sexual abuse and lived in shelters upon court order, due to the lack of maternal protection, as the mothers: a) denied the victimization and continued living with the perpetrators as their partners/wives or b) blamed the victims and considered the perpetrator was innocent, in the belief that the sexual abuse resulted from the child's seductive attitudes. In addition, the people from the broader family content, such as aunts/uncles, justified that they could not house the victims as they could represent a threat to their own children.

The inclusion criteria considered: a) the occurrence of sexual abuse in which the perpetrator(s) involved the child for the sake of his own satisfaction through acts like touching, kissing, caressing the genital areas, masturbating, with or without digital penetration or with the genital organ in the vagina and/or anus; b) the perpetrator being at least five years older than the child; c) the abuse being proven and registered; d) the victims living in shelters due to maternal abandonment.

\subsection{Instruments}

Sociodemographic protocols and characteristics of the violence suffered-developed by the authors to collect information like age, gender, and to characterize the sexual abuse. The data from this protocol were collected from the documents/registers of each child and from the people responsible for the shelters.

Rorschach Method (Exner, 2003)—a personality research tool, consisting of 10 cards of paint blots, in which the subject is expected to answer the question "what does this look like?". Thus, the answers to the prob- 
lem-solving task can be understood from multiple viewpoints, including thematic content analysis.

\subsection{Procedure}

This study is an excerpt from a broader study developed by researchers from the states of Rio Grande do Sul, Mato Grosso and São Paulo. All ethical procedures were conducted. Approval for the research project was obtained from the Ethics Committee at University of Passo Fundo, under opinion 030/2013. To respond to the study objectives, the 12 Rorschach protocols were fully analyzed that showed quantitative differences in comparison with the normative data by Ribeiro, Semer and Yazigi (2012). The qualitative analysis of the responses took into account the expressions, mainly the use of qualifiers that emphasize a damage suffered, as well as the feelings of lack of protection and vulnerability.

\section{Results and Discussion}

To enhance the visibility of the findings, Tables 1-5 show the protocol containing the description on the ficcional names of the institutionalized children victims of sexual abuse (P), card number (Cr), and responses in the Rorschach, coded with the recurring variables $m, M O R, A G, S x$ and $A n$. Next, Table 1 shows the sexual abuse victims' responses containing the determinant $m$.

As can be observed in Table 1, the answers containing the determinant $m$ seem to express aspects related to the victimized children's suffering and abandonment, as an intense activity of unintentional disturbing ideas, anguishing thoughts, and impotence to impede situations that affect their own destiny (Exner, 2003; Weiner, 2003). Among the children's narratives that can illustrate what is being demonstrated, that is-feelings of persecuting anguish, threat and invasion of external forces, which affect an extremely fragile and vulnerable ego, the following stand out: "it was catching fire", "burning", "it was melting”, "pulling the flesh". These findings appoint the feelings of abandonment and impotence found in sexual abuse victims, also observed in the examples of

\begin{tabular}{|c|c|c|}
\hline $\boldsymbol{P}$ & $\mathbf{C r}$ & Responses \\
\hline Lia & VI & 11 -an explosion that is happening in the sea \\
\hline Lia & II & 3-two animals that were attacked and are bleeding \\
\hline Luiz & VIII & $\begin{array}{l}\text { 13-Two armadillos and they were climbing a branch and there foot was catching fire and they } \\
\text { were melting. He's pink (armadillo), there's his tail and two legs. }\end{array}$ \\
\hline Clara & VIII & $\begin{array}{l}10-\text { There are a lot of things pulling the meat (because of the blue color), there are two dogs } \\
\text { because the color contains a dog that gets all red. }\end{array}$ \\
\hline José & IX & 14-A man riding the bike, the tire was on fire and burning. \\
\hline
\end{tabular}

Obs. Legend of the variables: $P=$ protocol, $\mathrm{Cr}=\mathrm{Card}$.

Table 2. Description of responses with MOR content of the children victims of sexual abuse.

\begin{tabular}{|c|c|c|}
\hline $\boldsymbol{P}$ & $\mathbf{C r}$ & Responses \\
\hline Maria & I & 2-A dead man, because it seems, because he’s got legs. \\
\hline Maria & III & $\begin{array}{l}\text { 5-I'm seeing that like a shirt, it's a destroyed shirt, because his wife tears it, that's him putting } \\
\text { on the shirt to go to the party (could not tell the name). }\end{array}$ \\
\hline Paulo & VII & $\begin{array}{l}\text { 7-An animal too, which eats the rabbit's head. He also flies, the uncle killed him, he's dead, he } \\
\text { shot him. }\end{array}$ \\
\hline Clara & IX & 12-It's a bone that broke, because it's broken. \\
\hline Paulo & IX & 10-It's a dog, an animal killed the dog. \\
\hline Pedro & IX & $\begin{array}{l}\text { 9-It seems like a crocodile his name and here's his horn, it's because it's under the water too, } \\
\text { but he can't eat, because he's got his mouth sown. }\end{array}$ \\
\hline Maria & $\mathrm{X}$ & 13-A skirt, because the husband tears the skirt her skirt is torn. \\
\hline
\end{tabular}

Obs. Legend of the variables: $P=$ protocol, $\mathrm{Cr}=\mathrm{Card}$, $(\mathrm{S})$ use of blank space. 
Table 3. Description of responses with AG content of the children victims of sexual abuse.

\begin{tabular}{lll}
\hline $\boldsymbol{P}$ & Cr & Responses \\
João & I & 1-A mask to put on the face, he looks like he's angry, because he's scary, because of the eyes (S) and the nose (S). \\
Paulo & İ & 2-It's an animal, he takes the hair and pulls and eats, this is the foot. \\
Maria & IV & 6-This here is turning into a monster, he scares the children, that's his arm, that's his head, that's his leg. \\
Paulo & IV & 4-It's an animal too, he eats hair too, he fights with us, he flies. \\
Pedro & IV & 4-A black shoe with some balls that throws milk at us, he scares us. He stays at our house. \\
Clara & VI & 8-I don't know. It's this here (points to the stain), it's the kidney, because there's this white thing here, which is \\
Maria & VII & 9-This here is turning into a cockroach, it pricks the others, it's her head, that's her leg. \\
Luiz & IX & 14-That here looks like two men fighting, here's his hand and then there's his face, the nose, the mouth and the ear. \\
José & X & 15-two crabs, there's a lot of tails, hand, eye and mouth, and he wants to bite the ants to eat because he's hungry. \\
\end{tabular}

Obs. Legend of the variables: $P=$ protocol, $\mathrm{Cr}=$ card, $(\mathrm{S})$ use of blank space.

Table 4. Description of responses with direct or symbolic Sx content of the children victims of sexual abuse.

$\begin{array}{lll}\boldsymbol{P} & \text { Cr } & \text { Answers } \\ \text { Luiz } & \text { I } & \text { 3-It's a chicken, there's her tail and she's shitting, it's like chicken shit. } \\ & \text { II } & \text { 4-A rabbit (2), his ear, the tail, the leg, his hand and he's also shitting. } \\ \text { Clara } & \text { III } & \text { 5-It's an ass. Because of the color, because it is black. } \\ & \text { VI } & \text { is something entering the kidney, I don't know what it is. } \\ \text { Júlia } & \text { VII } & \text { 10-Two little girls, two buts, two ears, two heads, two nose and two mouths. } \\ \text { Clara } & \text { VII } & \text { 9-It's the private parts, the butt, the legs and the feet. } \\ & \text { VIII } & \text { 11-It's a butt because there’s the ball. }\end{array}$

Obs. Legend of the variables: $P$ = protocol, $\mathrm{Cr}=$ Card.

Table 5. Description of responses with An content of the children victims of sexual abuse.

\begin{tabular}{|c|c|c|}
\hline $\boldsymbol{P}$ & $\mathbf{C r}$ & Answers \\
\hline Júlia & I & 2-A white stain, that thing inside is a heart. Like a heart. \\
\hline José & I & 3-A body. There's a bone, there's her son, he's born and he leaves. \\
\hline Júlia & II & 3-Two hands and a head, two eyes (S), a throat, a wing and a tail, because it's a bird. \\
\hline Rui & II & 2-I don't know that one. A heart, because of this little thing here which I don't know the name. \\
\hline Clara & VI & $\begin{array}{l}\text { 2-I don't know. And this here (pointing to the card) is the kidney. Because there's this white thing here. It's } \\
\text { something entering the kidney, I don't know what it is. }\end{array}$ \\
\hline Pedro & VIII & $\begin{array}{l}8 \text { - That is a small dinosaur ( } 2 \text { ) and here is their heart, here is the head, he can't shake his head because it is } \\
\text { glued. The heart because it gets afraid of them, because it gets afraid of the jaguar. }\end{array}$ \\
\hline Ana & $\mathrm{X}$ & 11 - A body, that is the red blood and that is the bone. \\
\hline
\end{tabular}

Obs. Legend of the variables: $P=$ protocol, $\mathrm{Cr}=\mathrm{Card},(\mathrm{S})$ use of blank space.

answers with $m$ contents, "an explosion in the sea of war", "an explosion in the water", "tree falling on the floor", from the study by Scortegagna and Villemor-Amaral (2013).

These results also legitimize studies that show feelings of impotence towards the child's ineffective attempts to put an end to the maltreatment and the intrinsic stressful experiences of sexual abuse (Finkelhor \& Browne, 1985; Scortegagna \& Villemor-Amaral, 2009, 2012). It should be highlighted that the references to the $m$ movement are mainly concerning due to the anguish of destruction they transmit, which also presupposes the 
existence of problems in the affective bonds with the attachment figures (Alexander, 1992, 2009; Bowlby, 1973, 1980). The reactivation of the anguish of annihilation supports the morbid content found next, in Table 2.

The perception of a damaged or undignified body, of a fragmented or severely injured self, is evidenced in the MOR responses, in line with the literature (Gravenhorst, 2002; Scortegagna \& Villemor-Amaral, 2009, 2013). The qualitative approach seems to reveal the children's perceptions of a destroyed or badly functioning body, reflecting the identification with a damaged, dilacerated body.

The MOR answers of the children in this study seem to indicate that the abusive acts, perceived as highly intrusive, can compromise the development of the self. The lifelessness of the human representations suggests potential narcissistic weaknesses deriving from the lack of care (Lamb \& Edgar-Smith, 1994; Cassidy \& Mohr, 2001; Smith et al., 2010), and undoubtedly compromises the bases for the development of a dynamic internal model that guarantees good mental representations of the self, others and the world (Bowlby, 1980).

The recursive images evoked, such as "dead", "ruined”, "torn”, "broken”, "hole”, "head... because it's glued", "fear", "sown mouth", witness the bodily and mental damage, an extinguished body. These findings are in line with the narratives "it looks like a mouse that was killed", "he's dead because I see that he was crushed", found in the study by Gravenhorst (2002), and the narratives "dog run over", "crushed frog”, "crushed mouse", "crushed bat", "dead animals" found in the study by Scortegagna and Villemor-Amaral (2013), in which the high frequency of crushed objects reveals a two-dimensional body, without content, void. Next, Table 3 shows the $A G$ answers.

Beyond the representations of the self, the aggressive content exhibited in Table 3 seem to represent the interactions with the others, a hostile environment, loaded with aggressiveness, as exemplified in the answers "he looks like he’s angry", "frightening", "fight”, "two men fighting”. The narratives "pulls and eats", "something entering the kidney" and "throws milk on us, he’s scary", "stings", "eats the rabbit's head", "bite the ants to eat" not only contain aggressiveness, but also express sexual content.

These findings support the study by Scortegagna and Villemor-Amaral (2013), which also found aggressiveness and destructive trends in the narratives "attacking one another", "fighting”, "explosion”, "stones cast". The abusive sexual relations and the loss of figures of trust can contribute to the increase in reactions of hostility and anger, and in repetitive sexual behaviors (Finkelhor \& Browne, 1985), which confirms the use of the Rorschach to understand this misfortune from an idiographic perspective. Table 4 shows answers with direct or symbolic sexual content.

The sexual content observed in Table 4 can indicate how the victims perceive sexuality. The expressions "he’s shitting”, "black butt”, "butt”, "private parts... butt” represent sexual elements the victims manifest. The narrative "something entering the kidney" not only exemplifies a sexual component, but also indicates aggressive content, as can also be seen in the narratives "pulls and eats", "throws milk on us, he's scary", "stings", "eats the rabbit's head", "bite the ants to eat" (Table 3). The sexual responses can indicate a lack of prohibition in an adverse environment, as observed in earlier studies (Barnett et al., 2013; Gravenhorst, 2002; Scortegagna \& Villemor-Amaral, 2009, 2013; Perfect et al., 2011). The similarities of the responses with the study by Scortegagna and Villemor-Amaral (2013) are found in the narratives "it looks like a nipple", "it looks like the pelvis", "the butt down here", "taking her breasts", “destroyed nipple”, and in the study by Barnett et al. (2013) in the narratives "vaginal area", "two males... here are their penises".

In this study, answers with an anal sex tone are observed, as verified in the narratives containing the expression "fire", with the determinant $m$, described in Table 1. The answers with $m$ and unusual contents reported in other studies (Friedrich et al., 1997; Kaser-Boyd \& Evans, 2008; Kendall-Tackett et al., 1993) can also reflect early sexualization, as mentioned by Finkelhor and Browne (1985), as the center of the traumatic dynamics of sexual abuse. As mentioned, the problems in the mental development of sexual abuse victims signal the difficulties to organize an apparatus with distinguished spaces, and which remit to the victims' traumatic experiences with primary objects, with their body, with the others. The description of the An answers in Table 5 can help to clarify the effects of the trauma experienced with the first objects.

The lack of integration of the bodily representation, translated in the Rorschach by the lack of complete human reactions, by fragmented human reactions and mainly by the An answers, can be verified in Table 5 . The answers "inside it’s a heart”, "bone”, "throat”, "kidney" and the expression "a body. There's bone, there’s her son, he's born and he gets out”, beyond the anatomy content, exemplify a sexual concern, demonstrate weakness or the inexistence of a protective contingent that warrants the coherence of the mental apparatus, that can provide an identity and guarantee the borders of the I. 
The answers specifically mix the interior and exterior of the body and evidence a lack of integration of the self. The trauma experienced and the errors in the maternal function, in the narcissistic investment, result in inconsistencies in the limits of the children's I. The paralysis of the mind and action out of fear is clearly demonstrated in the answer "he can't shake his head because it's glued".

It is interesting to observe that the images evoked may be the witness of the psychic and physical damaged suffered, added to a profound feeling of fragility and lack of protection. In particular, this is what Bowlby (1973) advocates when he states that negligency of basic necessities from primary care personnel, which is experienced by the children victims of sexual abuse, results in a lack of integrated sense of self or in a sense of self as unworthy or even bad.

\section{Conclusions}

When considering word by word what is said in the composition of the image and the articulation of the answer, the findings illustrate the traumatic effects of the sexual abuse and the maternal abandonment in the specific content of the answers containing inanimate movement (m), morbid (MOR), aggressive (AG), sexual (Sx) and anatomy (An) contents, and attend to the objective this study proposes. Among the results, it is verified that the answers containing determinant $m$ suggested the presence of feelings of abandonment and impotence, indicating conflict and tension, resulting from the victimization. The narratives containing $M O R$, alluding to a damaged body, a fragmented self, in combination with expressions of sexual content, indicate problems in repression and early sexualization. The replies containing An appoint the weaknesses of the self, indicate the lack of a protective maternal contingent to guarantee the integrity of the mental apparatus and the good delimitation of the borders of the I, observed in the analysis of the children's statements that include the determinant $m$, and MOR and Sx contents.

The classification of these children's Rorschach protocols, in comparison with Brazilian normative data, evidence quantitative differences, but what appears more clearly from an ideographic viewpoint in these children's mental functioning are the expressions that stand out and that exemplify what is found in the theories. It can be observed that, in some children, one indicator predominates while, in others, another indicator is enhanced. To give an example, for Maria, it is the fear of violence and its destructive effects that stands out in the answers while, for Clara, the exposed, penetrable and penetrated body stands out. In Pedro, the fear of threatening figures and the impossibility to act predominate, associated with the feeling of impotence- "sown mouth, head glued"-, while, for Luiz, it is the eroticization of the anal zone that stands out in this answers.

These results ratify the validity of the Rorschach in an idiographic approach, in which the intention is to observe the subtleties and singularities in the way of expressing the self. As yet another one of the modalities to unveil mental suffering, the data from the qualitative analysis of the answers can help with evaluation practices and drive interventions, exactly because they can also take into account the singularities of each case. In addition, the method alludes to the awareness raising about the effects of sexual abuse and greater attention to the needs of each child and the context(s) he lives in.

Finally, although the qualitative approach is more aligned with an ideographic perspective and the study sample is relatively small, these results should serve as signs for further investigation, case by case. Studies should certainly continue and expand the number of participants. These studies can support the above or not and enrich the research and knowledge process in this area.

\section{References}

Alexander, P. C. (1992). Application of Attachment Theory to the Study of Sexual Abuse. Journal of Consulting and Clinical Psychology, 60, 185-195. http://dx.doi.org/10.1037/0022-006X.60.2.185

Alexander, P. C. (2009). Childhood Trauma, Attachment, and Abuse by Multiple Partners. Psychological Trauma: Theory, Research, Practice, and Policy, 1, 78-88. http://dx.doi.org/10.1037/a0015254

Barnett, D., Heinze, H. J., \& Arble, E. (2013). Risk, Resilience, and the Rorschach: A Longitudinal Study of Children Who Experienced Sexual Abuse. Journal of Personality Assessment, 95, 600-609. http://dx.doi.org/10.1080/00223891.2013.823437

Bick, J., Zajac, K., Rakton, M. E., \& Smith, D. (2014). Convergence and Divergence in Reports of Maternal Support Following Childhood Sexual Abuse: Prevalence and Associations with Youth Psychosocial Adjustment. Child Abuse \& Neglect, 38, 479-487. http://dx.doi.org/10.1016/j.chiabu.2013.11.010 
Bowlby, J. (1973). Attachment and Loss, Vol. 2: Separation. New York: Basic Books.

Bowlby, J. (1980). Attachment and Loss, Vol. 3: Loss. New York: Basic Books.

Briere, J. (2004). Psychological Assessment of Adult Posttraumatic States: Phenomenology, Diagnosis, and Measurement (2nd ed.). Washington DC: American Psychological Association. http://dx.doi.org/10.1037/10809-000

Cassidy, J., \& Mohr, J.J. (2001). Unsolvable Fear, Trauma, and Psychopathology. Clinical Psychology: Science and Practice, 8, 275-298. http://dx.doi.org/10.1093/clipsy.8.3.275

Cohen, J. A., \& Mannarino, A. P. (2000). Predictors of Treatment Outcome in Sexually Abused Children. Child Abuse \& Neglect, 24, 983-994. http://www.nctsnet.org/nctsn assets/Articles/11.pdf http://dx.doi.org/10.1016/S0145-2134(00)00153-8

Exner Jr., J. E. (2003). The Rorschach: A Comprehensive System (4th ed.). Volume I: Basic Foundations. New York: Wiley.

Finkelhor, D., \& Browne, A. (1985). The Traumatic Impact of Child Sexual Abuse: A Conceptualization. Journal of Orthopsychiatry, 55, 530-541. http://dx.doi.org/10.1111/j.1939-0025.1985.tb02703.x

Friedrich, W. N., Jaworski, T. M., Huxsahl, J. E., \& Bengtson, B. S. (1997). Dissociative and Sexual Behaviors in Children and Adolescents with Sexual Abuse and Psychiatric Histories. Journal of Interpersonal Violence, 12, 155-158. http://dx.doi.org/10.1177/088626097012002001

Gravenhorst, M. C. (2002). Rorschach Psychodiagnosis of Psychic Trauma in Sexually Abused Children. In A. AndronikofSanglade (Ed.), Rorschachiana XXV: Yearbook of the International Rorschach Society (pp. 77-85). Ashland, OH: Hogrefe \& Huber Publishers, VII.

Hadland, S. E., Werb, D., Kerr, T., Fu, E., Wang, H., Montaner, J. S., \& Wood, E. (2012). Childhood Sexual Abuse and Risk for Initiating Injection Drug Use: A Prospective Cohort Study. Preventive Medicine: An International Journal Devoted to Practice and Theory, 55, 500-504. http://dx.doi.org/10.1016/j.ypmed.2012.08.015

Kaser-Boyd, N., \& Evans, F. B. (2008). Rorschach Assessment of Psychological Trauma. In C. B. Gacono, \& B. Evans (Eds.), The Handbook of Forensic Rorschach Assessment (pp. 255-277). New York: Routledge.

Kendall-Tackett, K. A., Williams, L. M., \& Finkelhor, D. (1993). Impact of Sexual Abuse on Children: A Review and Synthesis of Recent Empirical Studies. Psychological Bulletin, 113, 164-180. http://dx.doi.org/10.1037/0033-2909.113.1.164

Lamb, S., \& Edgar-Smith, S. (1994). Aspects of Disclosure: Mediators of Outcome of Childhood Sexual Abuse. Journal of Interpersonal Violence, 9, 307-326. http://dx.doi.org/10.1177/088626094009003002

Molnar, B. E., Buka, S. L., \& Kessler, R. C. (2001). Child Sexual Abuse and Subsequent Psychopathology: Results from the National Comorbidity Survey. American Journal of Public Health, 91, 753-760. http://dx.doi.org/10.2105/AJPH.91.5.753

Perfect, M. M., Tharinger, D. J., Keith, T. Z., \& Lyle-Lahroud, T. (2011). Relations between Minnesota Multiphasic Personality Inventory - A Scales and Rorschach Variables with the Scope and Severity of Maltreatment among Adolescents. Journal of Personality Assessment, 93, 582-591. http://dx.doi.org/10.1080/00223891.2011.608754

Ribeiro, R. K. S. M., Semer, N. L., \& Yazigi, L. (2012). Rorschach Comprehensive System Data from a Sample of 211 Nonpatient Children in Brazil. Journal of Personality Assessment, 94, 267-275. http://dx.doi.org/10.1080/00223891.2011.653727

Scortegagna, S. A., \& Villemor-Amaral, A. E. (2009). Autopercepção no Rorschach de vítimas de abuso sexual infantil. Psico, 40, 328-336. http://revistaseletronicas.pucrs.br/ojs/index.php/revistapsico/article/viewFile/5736/4800

Scortegagna, S. A., \& Villemor-Amaral, A. E. (2012). The Use of the Rorschach Method in the Investigation of Sexual Abuse of Children. Paidéia (Ribeirão Preto), 22, 271-280. http://dx.doi.org/10.1590/S0103-863X2012000200013

Scortegagna, S. A., \& Villemor-Amaral, A. E. (2013). Traumatic Loss and Helplessness: Qualitative Analysis of Responses in the Rorschach. Psico-USF, 18, 1-12. http://dx.doi.org/10.1590/S1413-82712013000100002

Smith, D. W., Sawyer, G. K., Jones, L. M., Cross, T., McCart, M. R., \& Ralston, M. E. (2010). Mother Reports of Maternal Support Following Child Sexual Abuse: Preliminary Psychometric Data on the Maternal Self-Report Support Questionnaire (MSSQ). Child Abuse \& Neglect, 34, 784-792. http://dx.doi.org/10.1016/j.chiabu.2010.02.009

Weiner, I. B. (2003). Principles of Rorschach Interpretation (2nd ed.). Mahwah, NJ: Lawrence Erlbaum Associates Inc.

Zajac, K. M., Ralston, E., \& Smith, D. W. (2015). Maternal Support Following Childhood Sexual Abuse: Associations with Children's Adjustment Post-Disclosure and at 9-Month Follow-Up. Child Abuse \& Neglect, 44, 66-75.

http://dx.doi.org/10.1016/j.chiabu.2015.02.011 